\title{
Detecting the Differences in Responses of Stomatal Conductance to Moisture Stresses between Deciduous Shrubs and Artemisia Subshrubs
}

\author{
Qiong Gao', Mei ${ }^{12 *}{ }^{2 *}$ Chan $\mathrm{Zhou}^{3}$ \\ 1 Landscape Analysis and Modeling Group, National Laboratory of Earth Surface Processes and Resources Ecology, Beijing Normal University, Beijing, China, 2 Institute for \\ Tropical Ecosystem Studies, University of Puerto Rico - Rio Piedras, San Juan, Puerto Rico, United States of America, 3 College of Life Sciences, Liaoning University, \\ Shenyang, China
}

\begin{abstract}
Shrubs and subshrubs can tolerate wider ranges of moisture stresses in both soil and air than other plant life forms, and thus represent greater nonlinearity and uncertainty in ecosystem physiology. The objectives of this paper are to model shrub/subshrub stomatal conductance by synthesizing the field leaf gas exchanges data of 24 species in China, in order to detect the differences between deciduous shrubs and Artemisia subshrubs in their responses of stomatal conductance to changes in the moisture stresses. We revised a model of stomatal conductance by incorporating the tradeoff between xylem hydraulic efficiency and cavitation loss risk. We then fit the model at the three hierarchical levels: global (pooling all data as a single group), three functional groups (deciduous non-legume shrubs, deciduous legume shrubs, and subshrubs in Artemisia genus), and individual observations (species $\times$ sites). Bayesian inference with Markov Chain Monte Carlo method was applied to obtain the model parameters at the three levels. We found that the model at the level of functional groups is a significant improvement over that at the global level, indicating the significant differences in the stomatal behavior among the three functional groups. The differences in tolerance and sensitivities to changes in moisture stresses are the most evident between the shrubs and the subshrubs: The two shrub groups can tolerate much higher soil water stress than the subshrubs. The analysis at the observation level is also a significant improvement over that at the functional group level, indicating great variations within each group. Our analysis offered a clue for the equivocal issue of shrub encroachment into grasslands: While the invasion by the shrubs may be irreversible, the dominance of subshrubs, due to their lower resistance and tolerance to moisture stresses, may be put down by appropriate grassland management.
\end{abstract}

Citation: Gao Q, Yu M, Zhou C (2013) Detecting the Differences in Responses of Stomatal Conductance to Moisture Stresses between Deciduous Shrubs and Artemisia Subshrubs. PLoS ONE 8(12): e84200. doi:10.1371/journal.pone.0084200

Editor: Gil Bohrer, The Ohio State University, United States of America

Received August 22, 2013; Accepted November 13, 2013; Published December 30, 2013

Copyright: (C) 2013 Gao et al. This is an open-access article distributed under the terms of the Creative Commons Attribution License, which permits unrestricted use, distribution, and reproduction in any medium, provided the original author and source are credited.

Funding: The National Science Foundation of China grants \# 41171445 and 41321001 , National Lab of Earth Surface Processes and Resources Ecology grant \# 2012-TDZY-31, National Basic Research Project \# 2014CB954303. The funders had no role in study design, data collection and analysis, decision to publish, or preparation of the manuscript.

Competing Interests: The authors have declared that no competing interests exist.

* E-mail: meiyu@ites.upr.edu

\section{Introduction}

Dynamic global vegetation models (DGVMs) and regional ecosystem models have been making projections of structures and functions in response to changes in climate and anthropogenic activities [1,2]. However, there existed great disagreements among the models, largely due to the uncertainties in physiological parameters that control the carbon assimilation into and emission out of ecosystems [3]. Ecosystem model parameters are often derived from plant functional traits, which have been recognized as important links to ecosystem functions, structures, and adaptations [4,5]. Relationships among maximum leaf photosynthesis, maximum stomatal conductance, specific leaf area, leaf life span, leaf size, and leaf nitrogen have been found from the global leaf traits dataset by means of meta-analyses $[6,7,8,9]$. Shrubland ecosystem physiology in the sub-humid, semiarid, and arid regions involves great uncertainty because of the superior tolerance to moisture stresses, morphological plasticity, and adaptability [10].

Shrubs have been reported to invade grasslands in many places over the world $[10,11,12,13,14,15]$. Many causal factors have been hypothesized to trigger the processes of shrub encroachment. Among these hypotheses, increased drought frequency and shifted rainfall seasonality/intensity have been considered as major drivers [16,17]. These hypotheses are based on a common assumption that shrubs are more tolerant to drought than grasses. The parameterized stomatal model used in the Patch Arid Land Simulator (PALS) [18,19] showed that the shrub stomata can tolerate much more severe soil water stress than the grass stomata. When soil moisture is ample, the grasses showed greater stomata conductance than the shrubs.

Shrubs tend to have deep roots, high ratio of leaf to sapwood areas, low vertical shading, and strong morphological plasticity to adapt to variations in climate and soils [20]. The same shrub species can be phreatophyte in sandy soils, but xerophyte in heavy clayey soils to maintain active when soil water potential lower than $-5 \mathrm{MPa}[21,22]$.

Models of stomatal conductance are important tools to quantify leaf production processes of shrubs, since leaf photosynthesis is colimited by stomatal conductance and biochemical carboxylation [23]. Many stomatal models exist in the literature, with different 
mechanistic/empirical assumptions and treatments. Ball et al. [24] proposed a simple empirical model of stomatal conductance as a function of net photosynthesis rates and relative humidity on leaf surface. Another model was developed to count the composite effects of net photosynthesis, vapor pressure deficit, and $\mathrm{CO}_{2}$ pressure on stomatal conductance [25]. More mechanistic model of stomatal conductance that considered the transient response of stomatal conductance to changes in driving variables was developed by Buckley et al. [26,27] Incorporating stomatal conductance with hydrological structure and function of tree canopy showed complex interactions between crown structure and hydrological function [28].

A semi-mechanistic model was developed by Gao et al. [29] to calculate stomatal conductance as a function of soil water potential, vapor pressure deficit in air, intercellular $\mathrm{CO}_{2}$ concentration, and light irradiance. The model was revised [30] to consider the cavitation loss of xylem conductance and hydrological capacitance, the model considered the cavitation loss of xylem hydraulic conductivity linearly dependent on xylem water potential, so that

$$
K_{\text {soil-to-leaf }}=g_{p}\left(1+\zeta \psi_{x}\right)
$$

where $K_{\text {soil-to-leaf }}$ is the apparent soil-to-leaf conductance, $g_{p}$ is the maximum conductance, and $\zeta$ is the parameter signifying the linear dependence of $K_{\text {soil-to-leaf }}$ on $\psi_{x}$, the xylem water potential. However, recent prevailing literatures on functional anatomy of plant xylem of various life forms revealed that the loss of xylem hydraulic conductivity due to cavitation and embolism is significantly related to the vessel diameters $[31,32,33,34,35,36,37,38]$, despite of some equivocal results with insignificant relationship from a few studies $[39,40]$. According to the prevailing literatures, vessels with larger diameter provide greater hydraulic conductivity, however, larger vessels are more prone to cavitation damage by negative pressure inside. Therefore, there exists a tradeoff between the hydraulic conductivity and its sensitivity to cavitation loss. The results of these experiments also indicated that the whole-plant (soil-to-leaf) conductivity decays exponentially with the xylem pressure, rather than the linear assumption in the previous stomatal models.

In this paper, we revised the model of stomatal conductance by Gao et al. [29,30] according to the prevailing literatures to reflect the tradeoff between the hydraulic efficiency and cavitation resistance. We then fit the revised model using the field diurnal measurements of leaf gas exchange of 24 shrub species in China to test the hypothesis that shrub functional groups differ significantly in their stomatal responses to changes in source (soil) and air moisture stresses. The results indicated that the three shrub functional groups (deciduous non-legume, deciduous legume, and Artemisia subshrubs) were significantly different in stomatal behavior. The sensitivities of stomatal conductance of the three shrub functional groups to relevant driving variables were calculated and discussed in the context of experimental evidences.

\section{Methods}

\section{The Model}

We revised the model of stomatal conductance by Gao et al. [30] so that the dependence of soil-to-leaf hydraulic conductance $\left(K_{\text {soil-to-leaf }}\right)$ on xylem water potential $\left(\psi_{x}\right)$ is hyperbolic rather than linear, and that the loss of xylem hydraulic conductance depends on the maximum soil-to-leaf conductivity $\left(g_{p}\right)$. Specifically,

$$
K_{\text {soil-to-leaf }}=\frac{g_{p}}{1-\lambda \psi_{x}}
$$

where $\lambda$ is a parameter. Moreover, we assumed $\lambda$ is proportional to $g_{p}$, i.e. $\lambda=C_{\lambda} g_{p}$, so that

$$
K_{\text {soil-to-leaf }}=\frac{g_{p}}{1-C_{\lambda} g_{p} \psi_{x}}
$$

where $C_{\lambda}$ is a constant across all species and all levels of the analysis. This formulation allowed us to balance the hydraulic conductance and the xylem safety, hence the greater the gp, the more vulnerable the xylem system.

In addition to the above changes, the osmotic adjustment is now dependent on net photosynthesis $A_{n}$ rather than light intensity $I_{p}$ [41], so that the osmotic pressure of plant leaf and guard cells, $\pi$, is

$$
\pi=\pi_{0}\left(1+\xi \frac{A_{n}}{K_{i}+A_{n}}\right)\left(\frac{C_{0}}{C_{i}}\right)
$$

where $\pi_{0}$ is the baseline osmotic pressure $(\mathrm{MPa}), C_{i}$ and $C_{0}$ are the intercellular and reference $\mathrm{CO}_{2}$ concentrations, respectively, and $\xi$ and $K_{i}$ are parameters. The model now takes similar treatment as Ball et al. [24,25].

The assumptions in the previous model [30] include: stomatal conductance, $g_{s}$, is proportional to the leaf turgor pressure $P_{\text {turgor }}$,

$$
g_{s}=K_{\psi} P_{\text {turgor }}=K_{\psi}\left(\pi+\psi_{x}\right)
$$

where $K_{\psi}$ is the apparent compliance of guard cell structure; and transpiration is the product of stomatal conductance and the scaled vapor pressure deficit $(D)$, i.e. the absolute vapor pressure deficit $(V P D)$ divided by air pressure $(P)$.

The mass balance between leaf transpiration and soil-to-leaf flow gives the equation

$$
\frac{g_{p}}{1-C_{\lambda} g_{p} \psi_{x}}\left(\psi-\psi_{x}\right)=K_{\psi}\left(\pi+\psi_{x}\right) D
$$

where $\psi$ is the soil water potential. Solving the Equation (5) for $\psi_{x}$ and substituting the result in (4) give the following model

$$
g_{s}=\frac{b-\sqrt{b^{2}-4 a c}}{2 a}
$$

where

$$
\begin{gathered}
a=C_{\lambda} D \\
b=1+\left(1 / g_{p}+C_{\lambda} \pi\right) K_{\psi} D
\end{gathered}
$$

$$
c=K_{\psi}(\pi+\psi)
$$

Equations (3, 6-9) constitute the complete model with 3 basic parameters of $K_{\psi}, g_{p}$, and $C_{\lambda}$, and three osmotic adjustment parameters of $\pi_{0}, K_{i}$, and $\xi$. 


\section{Data Collection and Preparation}

This analysis used the field diurnal gas exchange data of shrub leaves in northern China (Table 1). Part of the data were collected by the authors and colleagues during 2002-2007, and others were reported in the literature from 1990 to 2003. All the field measurements were done in public lands with free access to researchers. No specific permissions were required since the experiments had no obvious impacts on the sites and did not involve any endangered or protected species. The data from literature were read from tables and charts. Measurement on one species at a site is called an observation, and an observation may be done in multiple days. Each observation produced a data table with a number of variables (columns) including stomatal conductance/resistance, net photosynthesis, air pressure, and vapor pressure deficit, at leaf surface. Each record (row) in the data table represented one replicate of measurements on one plant leaf surface at specific hour of the day. There were a total of 43 observations within 80 diurnal measurements involving 24 species in this analysis. Table 1 also listed the approximate geographic location, elevation, instrument used, and data source. Data measured by the authors and colleagues are provided in Table S1.

To facilitate the analysis, all datasets of the diurnal measurements were converted to the formats and units used by the portable photosynthesis system Licor-6400 (Licor, Nebraska, USA). To avoid the problem of repeated measurements on the same plant leaf, the records of all data tables were averaged for each leaf at a particular hour.

\section{Procedures of Analysis}

The observations were grouped into three functional groups: non-legume deciduous shrubs (DCDS), deciduous legume shrubs (LEGM, mostly in Caragana genus), and subshrubs (SUBS, Artemisia genus). The LEGM group, with their potential nitrogen fixation capability, may be advantageous over the DCDS when nitrogen is limiting. The subshrubs have characteristics of both woody and herbaceous plants (woody based but herbaceous primary growth).

The above model of stomatal conductance was fitted to the data at three hierarchical levels: observations (OBS, species cross sites), functional groups (PFT), and global (GLB, pooling all data into a single group). Parameter $C_{\lambda}$ is treated as a super parameter for all the species and observations, so that the tradeoff between conductivity and xylem safety is realized. Model parameters were estimated by means of Bayesian Inference using Gibbs sampling with Markov Chain Monte Carlo (MCMC), implemented in the WinBUGS program $[42,43]$ run within the free software of $R$ [44].

Fitting the stomatal conductance model required the data for soil water potential which is not available. To get around the problem, we made an additional assumption that soil water potential is approximately constant for each day and the daily soil water potentials were estimated at the observation level. The assumption behind this treatment is that minimizing the difference between the model and the data should also allow us to estimate both model parameters and the unknown daily soil water potential $[29,30]$. The estimated daily soil water potentials from the observation level were used at the levels of GLB and PFT.

MCMC requires specification of prior probability distributions for the parameters. On the other hand, it is generally difficult for the iterations to converge to the physiologically meaningful results because of the nature of nonlinear models. We handled this difficulty by providing priors of uniform distributions within the specified physiologically meaningful ranges. This allowed us to place the following bounds to the parameters: $K_{\psi} \in[0.01,1.5] \mathrm{mol}$ $\mathrm{H}_{2} \mathrm{O} \mathrm{m} \mathrm{s}^{-1} \mathrm{MPa}^{-1}, g_{p} \in[0.1,60] \mathrm{mol} \mathrm{H}_{2} \mathrm{O} \mathrm{m} \mathrm{s}^{-1} \mathrm{MPa}^{-1}$,
$K_{i} \in[0.02,500] \quad \mu \mathrm{mol} \quad \mathrm{CO}_{2} \quad \mathrm{~m}^{-2} \quad \mathrm{~s}^{-1}, C_{\lambda} \in[1,10] \mathrm{mmol}^{-1} \mathrm{~m}^{2} \mathrm{~s}$, $\pi_{0} \in[0.01,2.0] \mathrm{MPa}$, and $\xi \in[0.1,500]$. The parameter $C_{\lambda}$ was only fitted at the observation level, so that the parameter at the other two levels (PFT and GLB) was fixed at the mean value from the observational fit. Since the previous studies have recognized the higher drought tolerance of shrubs than other functional types, we placed the bounds of daily soil water potential as $\psi \in[-0.03,-3.5]$ $\mathrm{MPa}$. These bounds were realized in the specification of uniform prior distribution. For example, a statement in the WINBUGS program, $\sim$ dunif $(0.01,1.5)$ specifies that the prior for the parameter $K_{\psi}$ is a uniform distribution between 0.01 and $1.5 \mathrm{~mol}$ $\mathrm{m}^{-2} \mathrm{~s}^{-1} \mathrm{MPa}^{-1}$. For each level of the hierarchical analysis, the MCMC was iterated for 5,000 times so that almost all parameters can converge.

\section{Results}

\section{The Statistics of the Fitted Models and Parameters}

Summary statistics (Table 2) for the analysis at the three levels indicate that from global to shrub functional groups to individual observations, the deviances of the models decrease, while the number of parameters increases. The deviance for stomatal model is negative because most measured and predicted stomatal conductance are smaller than 1. Specifically, the deviance decreased from $-1,423$ to $-1,804$ to $-3,981$, and the standard error of the residual decreased from 0.170 to 0.158 to $0.095 \mathrm{~mol}$ $\mathrm{m}^{-2} \mathrm{~s}^{-1}$, for GLB, PFT, and OBS levels, respectively. Smaller deviances indicate better fits of the models to the data, in the price of increased model complexity with more parameters. The difference in deviances between any two hierarchical levels has been shown to follow the $\chi^{2}$ distribution with the degrees of freedom equal to the difference in number of parameters between the two levels. Significant differences in model quality between the two hierarchical levels should be indicated in a significantly large $\chi^{2}$ value. The deviance tests (Table 2) among the three levels, viz. PFT vs. GLB, and OBS vs. PFT, indicate that the model for shrub functional groups (PFT) is a significant improvement over the global model (GLB), and that there is significant difference in behavior of stomatal conductance among the three shrub functional groups. Similarly, the model at the observation level is significantly better than the models at the level of functional groups. The trend of improved model fit from global to functional groups to observations is further demonstrated in the increased correlations between the model predictions and measurements (Table 2). Specifically the Pearson's correlation coefficient between the measured and predicted stomatal conductance increased from 0.61 to 0.70 to 0.90 (Fig. 1) as the analyses went from global to functional groups to observation levels. The plot of the model predicted against the measured stomatal conductance (Fig. 1) showed the progressive improvement of the fitting from coarse to fine granularity.

The obtained parameters of the stomatal model at the observation level (Table 3) showed wide ranges of variations across species and sites. Differences in plant and leaf ages, water and nutrient status, instruments used, completeness and accuracy of the data, timing of measurements, and instability of nonlinear algorithms, might all have contributed to these large variations. The super parameter $C_{\lambda}$ is $3.13 \pm 1.66\left(\mathrm{~m}^{2} \mathrm{~s} \mathrm{~mol}^{-1}\right)$.

Despite that we used the independent uniform prior distributions for the model parameters, we detected significant negative correlations between the fitted parameters $K_{\psi}$ and $g_{p}(\mathrm{r}=-0.44$, $\mathrm{p}=0.002)$, and between $\pi_{0}$ and $\mu(\mathrm{r}=-0.44, \mathrm{p}=0.0015)$, and positive correlations between parameters $K_{\psi}$ and $\pi_{0}(\mathrm{r}=0.33$, $\mathrm{p}=0.021)$, between $g_{p}$ and $K_{i}(\mathrm{r}=0.44, \mathrm{p}=0.073)$. The negative 
Table 1. List of data sources. PFT - plant functional type, $\mathrm{N}$ - number of records.

\begin{tabular}{|c|c|c|c|c|c|c|c|c|}
\hline Observation & Species & PFT & $\mathbf{N}$ & Latitude & Longitude & Elevation (m) & Instrument & Reference \\
\hline 1 & Chimonanthus praecox (L.) Link & DCDS & 24 & & & & & [59] \\
\hline 2 & Mussaenda esquirolli Levl. & DCDS & 47 & 109.61 & 26.85 & 500 & LI- 6400 & Measured \\
\hline 3 & Syringa pekinensis Rupr. & DCDS & 53 & 115.48 & 40.02 & 1100 & LI-6400 & \\
\hline 4 & Lespedeza bicolor Turcz. & LEGM & 44 & 115.48 & 40.02 & 1100 & LI-6400 & \\
\hline 5 & Vitex negundo Linn. & DCDS & 53 & 115.48 & 40.02 & 1100 & LI-6400 & \\
\hline 6 & Caragana pygmaea (Linn.) DC. & LEGM & 176 & 112.7 & 42.71 & 1100 & LI-6400 & \\
\hline 7 & Caragana korshinskii Kom. & LEGM & 72 & 112.7 & 42.71 & 1100 & LI-6400 & \\
\hline 8 & Caragana intermedia Kuang et $\mathrm{H}$. C. Fu & LEGM & 72 & 112.7 & 42.71 & 1100 & LI-6400 & \\
\hline 9 & Artemisia frigida Willd. & SUBS & 122 & 112.7 & 42.71 & 1100 & LI- 6400 & \\
\hline 10 & Artemisia frigida Willd. & SUBS & 82 & 112.7 & 42.71 & 1100 & LI-6400 & \\
\hline 11 & Artemisia frigida Willd. & SUBS & 124 & 112.7 & 42.71 & 1100 & LI-6400 & \\
\hline 12 & Caragana microphylla Lam. & LEGM & 144 & 115.47 & 42.12 & 1350 & LI- 6400 & \\
\hline 13 & Artemisia frigida Willd. & SUBS & 169 & 115.47 & 42.12 & 1350 & LI-6400 & \\
\hline 14 & Salix psammophila C. Wang et Ch. Y. Yang & DCDS & 36 & 109.19 & 39.49 & 1300 & LI-6400 & \\
\hline 15 & Artemisia ordosica Krasch. & SUBS & 36 & 109.19 & 39.49 & 1300 & LI-6400 & \\
\hline 16 & Hedysarum fruticosum Pall. & LEGM & 72 & 109.19 & 39.49 & 1300 & LI- 6400 & \\
\hline 17 & Caragana intermedia Kuang et $\mathrm{H}$. C. Fu & LEGM & 72 & 116.73 & 43.55 & 1200 & LI-6400 & \\
\hline 18 & Salix psammophila C. Wang et Ch. Y. Yang & DCDS & 72 & 116.73 & 43.55 & 1200 & LI-6400 & \\
\hline 19 & Lespedeza potaninii Vass. & LEGM & 69 & 116.73 & 43.55 & 1200 & LI-6400 & \\
\hline 20 & Hippophae rhamnoides Linn. & DCDS & 72 & 116.73 & 43.55 & 1200 & LI-6400 & \\
\hline 21 & Artemisia oxycephala Kitag. & SUBS & 32 & 116.7 & 43.63 & 1200 & $\mathrm{Cl}-301 \mathrm{PS}$ & [60] \\
\hline 22 & Paeonia suffruticosa Andr. & DCDS & 36 & 115.42 & 39.97 & 100 & Cl-301PS & [61] \\
\hline 23 & Caragana intermedia Kuang et $\mathrm{H}$. C. Fu & LEGM & 23 & 109.85 & 39.03 & 1300 & LI-6000 & [62] \\
\hline 24 & Artemisia ordosica Krasch. & SUBS & 24 & 109.85 & 39.03 & 1300 & LI-6000 & \\
\hline 25 & Lonicera maackii (Rupr.) Maxim. & DCDS & 13 & 116.37 & 39.93 & 50 & Cl-301 PS & [63] \\
\hline 26 & Lagerstroemia indica Linn. & DCDS & 13 & 116.37 & 39.93 & 50 & Cl-301 PS & \\
\hline 27 & Viburnum rhytidophyllum Hemsl. & DCDS & 13 & 116.37 & 39.93 & 50 & $\mathrm{Cl}-301 \mathrm{PS}$ & \\
\hline 28 & Sambucus williamsii Hance & DCDS & 13 & 116.37 & 39.93 & 50 & $\mathrm{Cl}-301 \mathrm{PS}$ & \\
\hline 29 & Artemisia frigida Willd. & SUBS & 7 & 120.75 & 42.88 & 500 & Cl-301 PS & [64] \\
\hline 30 & Caragana microphylla Lam. & LEGM & 7 & 120.75 & 42.88 & 500 & Cl-301 PS & \\
\hline 31 & Hippophae rhamnoides Linn. & DCDS & 48 & 109.25 & 36.71 & 1350 & LI-6400 & Measured \\
\hline 32 & Caragana korshinskii Kom. & LEGM & 36 & 109.25 & 36.71 & 1350 & LI-6400 & \\
\hline 33 & Lespedeza daurica (Laxm.) Schindl. & LEGM & 22 & 109.25 & 36.71 & 1350 & LI- 6400 & \\
\hline 34 & Caragana korshinskii Kom. & LEGM & 18 & 104.85 & 37.45 & 1300 & LI-6200 & [65] \\
\hline 35 & Artemisia ordosica Krasch. & SUBS & 18 & 104.85 & 37.45 & 1300 & LI-6200 & \\
\hline 36 & Hedysarum scoparium Fisch. et Mey. & LEGM & 13 & 104.85 & 37.45 & 1300 & Li-6200 & [66] \\
\hline 37 & Caragana korshinskii Kom. & LEGM & 13 & 104.85 & 37.45 & 1300 & Li-6200 & [67] \\
\hline 38 & Artemisia ordosica Krasch. & SUBS & 13 & 104.85 & 37.45 & 1300 & Li-6200 & \\
\hline 39 & Caragana korshinskii Kom. & LEGM & 21 & 104.95 & 37.33 & 1300 & Cl-301PS & [68] \\
\hline 40 & Caragana intermedia Kuang et $\mathrm{H}$. C. Fu & LEGM & 21 & 109.19 & 39.49 & 1300 & Cl-301PS & \\
\hline 41 & Caragana microphylla Lam. & LEGM & 21 & 120.92 & 42.38 & 1300 & Cl-301PS & \\
\hline 42 & Alhagi sparsifolia Shap. & DCDS & 42 & 86.2 & 38.37 & 1400 & LI-6400 & [69] \\
\hline 43 & Calligonum caput-medusae Schrenk & DCDS & 42 & 86.2 & 38.37 & 1400 & LI-6400 & \\
\hline
\end{tabular}

doi:10.1371/journal.pone.0084200.t001

correlation between $K_{\psi}$ and $g_{p}$ indicated that the stiffness of guard cell structure and efficiency of hydraulic conductance exhibit some kind of coordination. The more efficient vertical xylem transport, the stiffer the guard cell structure to keep the stomata open. It also reflects the balance between stomatal sensitivity to turgor pressure and xylem sensitivity to cavitation.

The obtained soil water potentials at the observation level (Fig. 2) were plotted as histograms of the three functional types. We found the mean and standard deviations of the soil water 
Table 2. Deviances calculated by the WINBUGS, and the Chi-square tests of deviances among the three levels (Global, Functional group, and Observation).

\begin{tabular}{|c|c|c|c|}
\hline Analysis Level & Global & Functional group & Observation \\
\hline Deviance & $-1,423$ & $-1,804$ & $-3,981$ \\
\hline Deviance Information Criterion & $-1,485$ & $-1,789$ & $-24,249$ \\
\hline Number of Parameters & 5 & 15 & 296 \\
\hline Standard deviation of error & 0.170 & 0.158 & 0.095 \\
\hline Difference in deviance & 378 & & 2,897 \\
\hline Difference in number of parameters & 10 & & 281 \\
\hline$p$-value of $\chi^{2}$ test & $<0.0001$ & & $<0.0001$ \\
\hline Correlation between measured and predicted stomatal conductance & 0.61 & 0.70 & 0.90 \\
\hline
\end{tabular}

potentials were $-0.94 \pm 0.49,-1.08 \pm 0.66$, and $-0.73 \pm 0.41 \mathrm{MPa}$ for DGDS, LEGM, and SUBS, respectively. The t test to compare the means between LEGM and SUBS resulted in a p-value of 0.024 , and the comparison between DCDS and SUBS resulted in a $\mathrm{p}$-value of 0.13 . The result indicates that the fitted soil water potentials for the subshrubs are significantly higher than the LEGM shrubs. The means of the soil water potential are not significantly different from each other between the LEGM and DCDS groups. The correlations among the model parameters reflect the complex interactions among various components involved in water transportation from soil to plant leaves [28].

At the functional group level (Table 4), the fitted mean compliance $K_{\psi}$ varied from 0.16 to 0.70 to 1.45 , reflecting the decreased stiffness of guard cell structure from DCDS to LEGM to

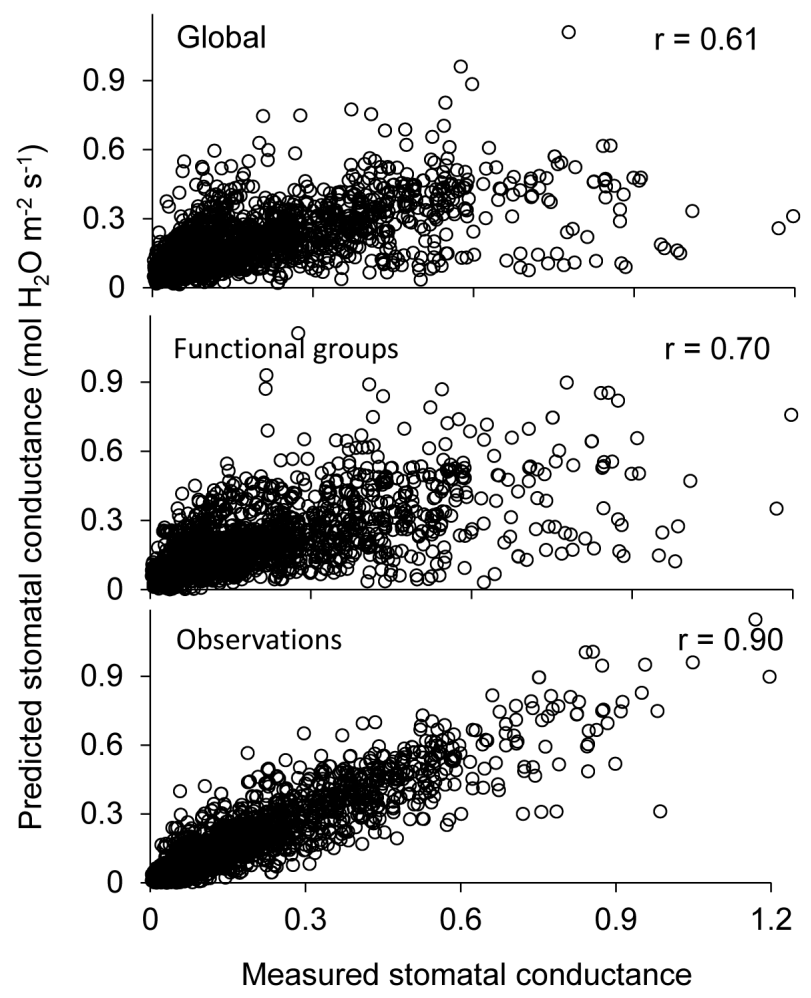

Figure 1. Model predicted vs. measured stomatal conductance at the three hierarchical levels.

doi:10.1371/journal.pone.0084200.g001
SUBS, respectively. However, the maximum potential soil-to-leaf conductance is the greatest for SUBS $\left(5.66 \mathrm{mmol} \mathrm{m}^{-2} \mathrm{~s}^{-1}\right.$ $\left.\mathrm{MPa}^{-1}\right)$, but the smallest for LEGM $\left(2.05 \mathrm{mmol} \mathrm{m} \mathrm{m}^{-2} \mathrm{~s}^{-1} \mathrm{MPa}^{-1}\right)$, with DCDS in between $\left(2.57 \mathrm{mmol} \mathrm{m}{ }^{-2} \mathrm{~s}^{-1} \mathrm{MPa}^{-1}\right)$.

While $\pi_{0}$ is the baseline osmotic pressure, the combination of $K_{i}$ and $\xi$ determines the extent and sensitivity of osmotic adjustment. The three functional groups have similar $\pi_{0}$ in the range of 1.87 to $1.94 \mathrm{MPa}$. The DCDS group is shown to have the smallest mean $K_{i}$ value $\left(198.8 \mu \mathrm{mol} \mathrm{CO} \mathrm{m}^{-2} \mathrm{~s}^{-1}\right)$, whereas the SUBS has $K_{i}$ of 319.3. The SUBS has the lowest $\xi$ (9.9) followed by 23.8 for DCDS and 34.1 for LEGM. Referring to Equation (3), the efficiency of osmotic adjustment is largely determined by the ratio of $\xi$ to $K_{i}$ since $K_{i}$ is much greater than the maximum net assimilation $\left(<20 \mu \mathrm{mol} \mathrm{m} \mathrm{m}^{-2} \mathrm{~s}^{-1}\right)$ in this case. The obtained model parameters at the global level (Table 4) mostly fall in the range of those at the level of functional groups, except for $\pi_{0}$ of 1.76 , which is smaller than any of the three functional groups.

\section{Behavior of the Stomatal Model}

Based on the model parameters at the levels of PFT and GLB, calculated stomatal conductance was plotted as functions of soil water potential and dimensionless vapor pressure deficit (Fig. 3), with leaf net assimilation fixed at $6.5 \mu \mathrm{mol} \mathrm{m} \mathrm{m}^{-2} \mathrm{~s}^{-1}$ (approximately the mean value of net photosynthesis for these groups). Sharp comparison among the three shrub functional groups exists. The lower right corners of the panels depict the maximum stomatal conductance at favorable moisture conditions with $\psi=-0.033 \mathrm{MPa}$ (approximately field capacity) and $D=0.0035$. At temperature of $30^{\circ} \mathrm{C}$ at the sea level, $D$ of 0.0035 means $91 \%$ of relative humidity. At these conditions, the subshrub has the highest stomatal conductance of $1.7 \mathrm{~mol} \mathrm{~m}^{-2} \mathrm{~s}^{-1}$ followed by the 1.1 of the LEGM group. However, the DCDS group has the much smaller stomatal conductance of $0.44 \mathrm{~mol} \mathrm{~m}^{-2} \mathrm{~s}^{-1}$. The GLB has the maximum stomatal conductance of $0.83 \mathrm{~mol} \mathrm{~m} \mathrm{~m}^{-2}$, slightly smaller than the average of the three functional groups. The ranking of these values is largely determined by the $K_{\psi}$ parameter (Table 4). When moisture conditions are favorable, greater guard cell compliance implies greater aperture of stomata, hence greater stomatal conductance.

The subshrub group has lower tolerance to soil water stress than the two deciduous shrub groups, as the stomatal conductance of SUBS closes at the soil water potential of $-2.2 \mathrm{MPa}$. In contrast, the stomatal conductance of DCDS and LEGM groups decrease to zero at -3.2 and $-3.5 \mathrm{MPa}$, respectively. However, the subshrub group has higher tolerance to vapor pressure deficit than the two deciduous shrub groups (Fig. 3). When the soil water 
Table 3. Obtained parameters of the stomatal model at individual observation level.

\begin{tabular}{|c|c|c|c|c|c|c|}
\hline Observation & PFT & $\kappa_{\psi}$ & $g_{p}$ & $K_{i}$ & $\pi_{0}$ & $\xi$ \\
\hline 1 & DCDS & 0.088 & 33.11 & 295.4 & 0.95 & 149.6 \\
\hline 2 & DCDS & 0.552 & 28.10 & 326.8 & 1.30 & 9.8 \\
\hline 3 & DCDS & 0.380 & 20.08 & 324.1 & 1.02 & 99.0 \\
\hline 4 & LEGM & 0.454 & 18.14 & 330.1 & 1.02 & 79.8 \\
\hline 5 & DCDS & 0.297 & 26.79 & 329.7 & 1.02 & 69.1 \\
\hline 6 & LEGM & 0.591 & 10.95 & 330.1 & 1.54 & 2.9 \\
\hline 7 & LEGM & 0.639 & 17.16 & 333.9 & 1.04 & 12.0 \\
\hline 8 & LEGM & 0.734 & 10.57 & 329.9 & 1.20 & 11.9 \\
\hline 9 & SUBS & 0.228 & 25.90 & 345.8 & 1.41 & 26.0 \\
\hline 10 & SUBS & 0.508 & 22.16 & 338.7 & 1.09 & 27.4 \\
\hline 11 & SUBS & 1.084 & 11.64 & 345.1 & 1.51 & 2.9 \\
\hline 12 & LEGM & 0.927 & 1.94 & 362.5 & 1.39 & 88.7 \\
\hline 13 & SUBS & 1.461 & 5.06 & 369.7 & 1.95 & 15.7 \\
\hline 14 & DCDS & 1.034 & 2.77 & 302.1 & 1.39 & 45.8 \\
\hline 15 & SUBS & 0.986 & 1.47 & 227.2 & 1.16 & 135.1 \\
\hline 16 & LEGM & 0.576 & 9.83 & 41.4 & 0.94 & 5.6 \\
\hline 17 & LEGM & 1.034 & 1.66 & 67.7 & 1.26 & 38.3 \\
\hline 18 & DCDS & 0.460 & 19.17 & 308.3 & 1.12 & 36.5 \\
\hline 19 & LEGM & 1.307 & 3.90 & 219.8 & 1.74 & 34.2 \\
\hline 20 & DCDS & 0.526 & 6.42 & 45.3 & 1.04 & 49.3 \\
\hline 21 & SUBS & 0.282 & 30.17 & 316.3 & 1.54 & 8.8 \\
\hline 22 & DCDS & 0.263 & 20.60 & 304.4 & 1.06 & 191.7 \\
\hline 23 & LEGM & 1.407 & 2.82 & 26.5 & 1.35 & 3.6 \\
\hline 24 & SUBS & 1.482 & 8.28 & 331.1 & 1.98 & 1.7 \\
\hline 25 & DCDS & 0.322 & 20.99 & 305.4 & 0.71 & 149.0 \\
\hline 26 & DCDS & 0.345 & 19.93 & 311.0 & 0.76 & 151.9 \\
\hline 27 & DCDS & 0.311 & 22.57 & 308.1 & 0.77 & 148.7 \\
\hline 28 & DCDS & 0.180 & 27.62 & 313.2 & 0.85 & 140.8 \\
\hline 29 & SUBS & 0.311 & 22.94 & 314.0 & 0.82 & 152.0 \\
\hline 30 & LEGM & 0.262 & 25.18 & 305.6 & 0.78 & 162.8 \\
\hline 31 & DCDS & 1.090 & 0.87 & 27.4 & 1.43 & 10.6 \\
\hline 32 & LEGM & 0.845 & 1.71 & 319.5 & 1.55 & 113.5 \\
\hline 33 & LEGM & 0.246 & 23.21 & 271.1 & 1.21 & 130.4 \\
\hline 34 & LEGM & 0.565 & 26.70 & 325.6 & 1.31 & 33.9 \\
\hline 35 & SUBS & 0.599 & 8.05 & 303.0 & 1.17 & 158.1 \\
\hline 36 & LEGM & 0.551 & 38.58 & 320.1 & 1.38 & 30.9 \\
\hline 37 & LEGM & 0.452 & 50.90 & 341.6 & 1.69 & 51.5 \\
\hline 38 & SUBS & 0.807 & 55.83 & 314.9 & 1.86 & 7.4 \\
\hline 39 & LEGM & 0.236 & 18.59 & 298.9 & 1.15 & 205.1 \\
\hline 40 & LEGM & 0.636 & 5.95 & 323.0 & 1.43 & 87.9 \\
\hline 41 & LEGM & 0.157 & 23.07 & 317.9 & 1.27 & 150.3 \\
\hline 42 & DCDS & 0.745 & 2.56 & 325.9 & 1.50 & 119.3 \\
\hline 43 & DCDS & 0.407 & 12.50 & 309.5 & 1.32 & 150.7 \\
\hline Mean & & 0.613 & 19.06 & 283.9 & 17.36 & 76.7 \\
\hline \multicolumn{2}{|c|}{ Standard deviation } & 0.373 & 13.96 & 93.0 & 12.95 & 63.5 \\
\hline \multicolumn{2}{|l|}{ Maximum } & 1.482 & 62.13 & 369.7 & 55.83 & 205.1 \\
\hline \multicolumn{2}{|l|}{ Minimum } & 0.088 & 1.04 & 26.5 & 0.87 & 1.7 \\
\hline
\end{tabular}

$C_{\lambda}$ is $3.13 \pm 1.66 \mathrm{~m}^{2} \mathrm{~s} \mathrm{~mol}^{-1}$. Units of the parameters: $K_{\psi}, \mathrm{mol} \mathrm{m}^{-2} \mathrm{~s}^{-1} \mathrm{MPa}^{-1}$, $g_{p}, \mathrm{mmol} \mathrm{m} \mathrm{m}^{-1} \mathrm{MPa}^{-1}, K_{i}, \mu \mathrm{mol} \mathrm{CO} \mathrm{m}^{-2} \mathrm{~s}^{-1}, \pi_{0}, \mathrm{MPa}$, and $\xi$ is dimensionless. doi:10.1371/journal.pone.0084200.t003

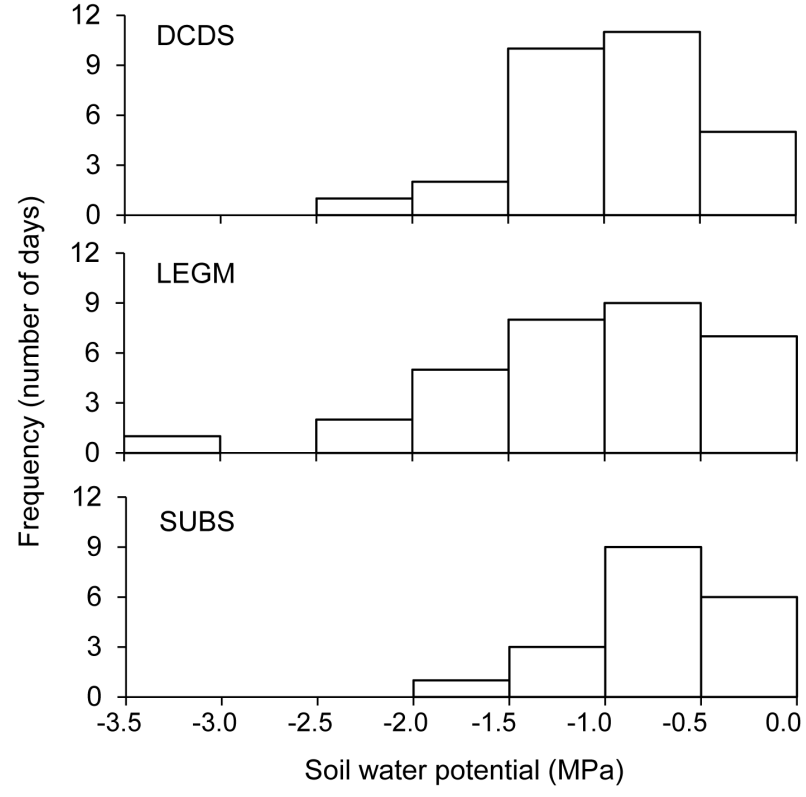

Figure 2. Histograms of the fitted soil water potentials for the three functional groups.

doi:10.1371/journal.pone.0084200.g002

potential is high $(-0.033 \mathrm{MPa})$ but the scaled vapor pressure deficit is great (0.05), the subshrub group maintains greater stomatal conductance $\left(0.23 \mathrm{~mol} \mathrm{~m} \mathrm{~s}^{-2} \mathrm{~s}^{-1}\right)$ than the two deciduous shrub groups (approximately $0.14 \mathrm{~mol} \mathrm{~m}^{-2} \mathrm{~s}^{-1}$ ).

The tolerance to soil water stress is primarily determined by the osmotic pressure and the compliance of guard cell structure. The SUBS has low tolerance to soil water stress largely because of the greatest $K_{\psi}$ which makes the stomata sensitive to changes in soil water stress.

The spacing and slope of the contour lines (Fig. 3) represent the relative sensitivities of stomatal conductance with respect to soil water stress and vapor pressure deficit. The response of stomatal conductance to vapor pressure deficit is determined by the ratio of

Table 4. Parameters of the stomatal model estimated by the WinBUGS at the global (GLB) and the functional group levels.

\begin{tabular}{|c|c|c|c|c|c|}
\hline Parameter & & GLB & DCDS & LEGM & SUBS \\
\hline \multirow[t]{2}{*}{$K_{\psi}$} & mean & 0.38 & 0.16 & 0.70 & 1.42 \\
\hline & STD & 0.10 & 0.03 & 0.27 & 0.15 \\
\hline \multirow[t]{2}{*}{$g_{p}$} & mean & 3.60 & 2.57 & 2.05 & 5.66 \\
\hline & STD & 3.70 & 1.19 & 0.90 & 2.37 \\
\hline \multirow[t]{2}{*}{$K_{i}$} & mean & 202.6 & 198.8 & 284.0 & 319.8 \\
\hline & STD & 129.5 & 142.5 & 130.0 & 122.8 \\
\hline \multirow[t]{2}{*}{$\pi_{0}$} & mean & 1.76 & 1.91 & 1.94 & 1.87 \\
\hline & STD & 0.39 & 0.08 & 0.17 & 0.23 \\
\hline \multirow[t]{2}{*}{$\xi$} & mean & 25.5 & 23.8 & 34.1 & 9.9 \\
\hline & STD & 48.6 & 15.9 & 17.3 & 11.5 \\
\hline $\mathbf{N}_{\text {day }}$ & 80 & & 24 & 36 & 20 \\
\hline $\mathbf{N}$ & 2119 & & 576 & 916 & 627 \\
\hline$N_{\text {obs }}$ & 43 & & 15 & 18 & 10 \\
\hline
\end{tabular}



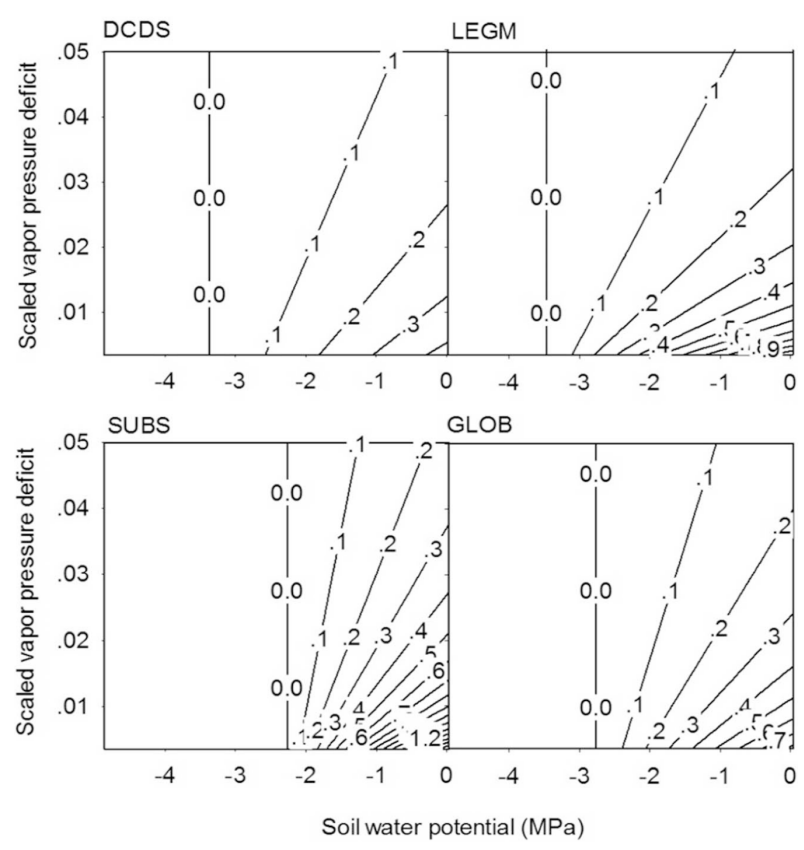

Figure 3. Stomatal conductance (contour lines, $\mathrm{mol}_{2} \mathrm{O} \mathrm{m}^{-2}$ $s^{-1}$ ) as functions of soil water potential and scaled vapor pressure deficit for the three shrub functional groups, calculated based on the parameters obtained at the level of functional groups: the deciduous non-legume shrubs (DCDS), the deciduous legume shrubs (LEGM), and the Artemisia subshrubs (SUBS). The stomatal conductance calculated from the global level model (GLOB) is also plotted as the comparison. Net assimilation $A_{n}$ is fixed at $6.5 \mu \mathrm{mol} \mathrm{CO}_{2} \mathrm{~m}^{-2} \mathrm{~s}^{-1}$.

doi:10.1371/journal.pone.0084200.g003

$K_{\psi}$ to $K_{\text {soil-to-leaf }}$, so that greater $K_{\psi}$ but smaller $K_{\text {soil-to-leaf }}$ makes the stomatal conductance more sensitive to VPD. A smaller $K_{\text {soil-to-leaf }}$ tends to cause insufficient water supply from roots to leaves under greater VPD, and the insufficient water supply decreases the leaf xylem water potential, turgor pressure, and stomatal conductance. A greater $K_{\psi}$ will make stomata more sensitive to the decrease in the turgor pressure, so that the stomatal conductance decreases faster with VPD. The LEGM and SUBS groups have high sensitivity to vapor pressure deficit, largely because the former has the smallest $g_{p}$ (maximum $K_{\text {soil-to-leaf }}$ ), and the latter has the greatest $K_{\psi}$ values. The DCDS group has a small $g_{p}\left(2.57 \mathrm{mmol} \mathrm{m}^{-2} \mathrm{~s}^{-1} \mathrm{MPa}^{-1}\right)$, however, it also has a small $K_{\psi}\left(0.16 \mathrm{~mol} \mathrm{~m}^{-2} \mathrm{~s}^{-1} \mathrm{MPa}^{-1}\right)$, so that the stomatal conductance is not as sensitive as LEGM or SUBS.

We also used the fitted parameters at the observation level to calculate stomatal conductance of all the observations, and plotted the arithmetic means and one standard deviation below and above against soil water potential (Fig. 4) and scaled vapor pressure deficit (Fig. 5). The results confirmed the findings at the level of functional groups. The average stomatal conductance of DCDS, LEGM, and SUBS close approximately at $-4,-3.6$, and -3 $\mathrm{MPa}$, respectively, so that the tolerance and sensitivity to soil water stress and vapor pressure deficit of the three functional groups follow the same ranks in Fig. 3.

Finally the comparison of mean $K_{\text {soil-to-leaf }}$ as a function of xylem water potential based on the parameters obtained at the observation level (Fig. 6) shows similar characteristics for the three functional groups. However, the calculated $\psi_{x, 50}$ values, at which $K_{\text {soil-to-leaf }}$ decreased by a half of its maximum value, are -12.3 ,

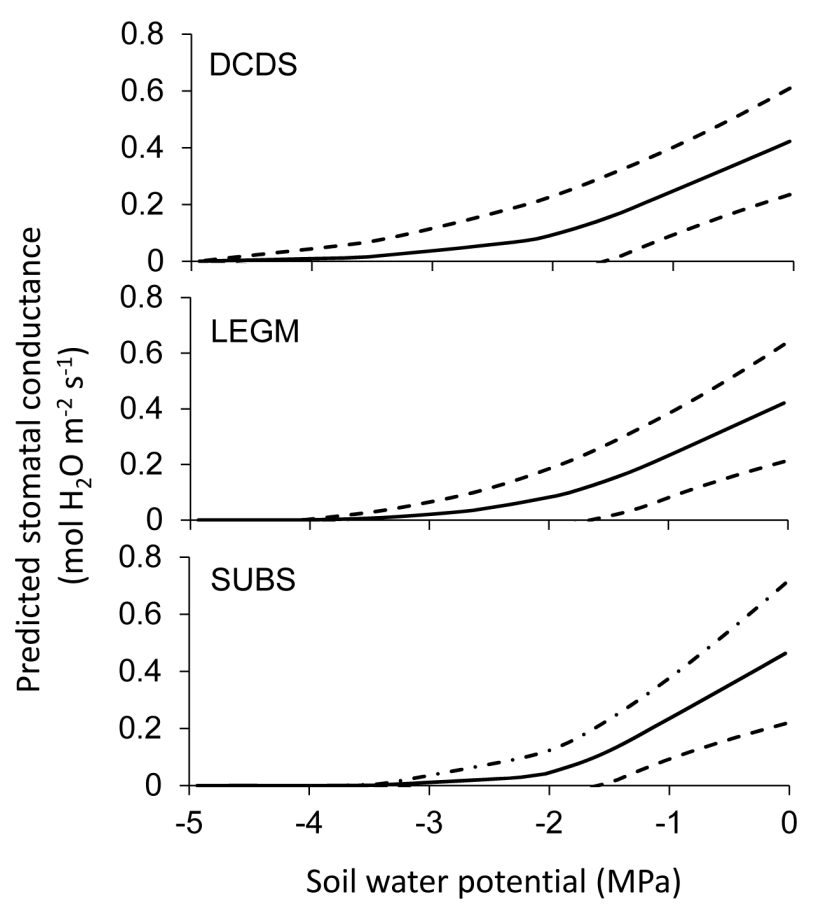

Figure 4. Predicted stomatal conductance as functions of soil water potential based on the parameters at the observation level. The scaled vapor pressure deficit is fixed at 0.03 and the net assimilation at $6.5 \mu \mathrm{mol} \mathrm{CO}_{2} \mathrm{~m}^{-2} \mathrm{~s}^{-1}$, for all individual observations. The solid line stands for the mean, and the broken lines indicate one standard deviation below and above the mean. doi:10.1371/journal.pone.0084200.g004

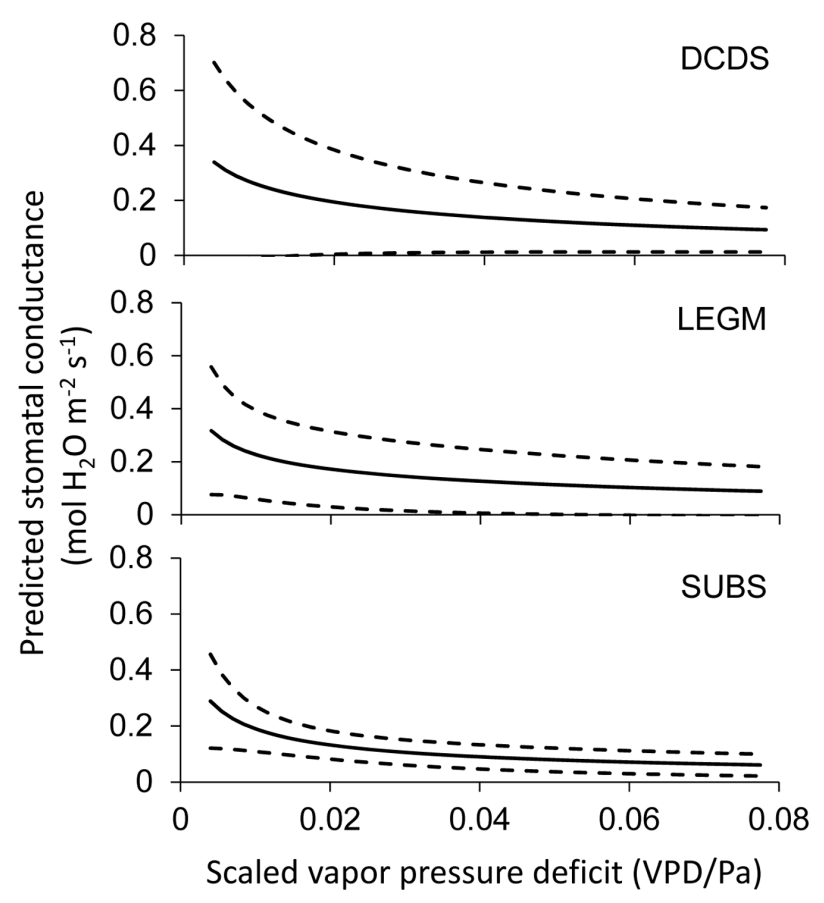

Figure 5. Predicted stomatal conductance as functions of scaled vapor pressure deficit based on the parameters at the observation level. The soil water potential is fixed at $-1.0 \mathrm{MPa}$ for all individual observations, and net assimilation is treated as the same as in Fig. 3. The solid line stands for the mean, and the broken lines indicate one standard deviation below and above the mean.

doi:10.1371/journal.pone.0084200.g005 


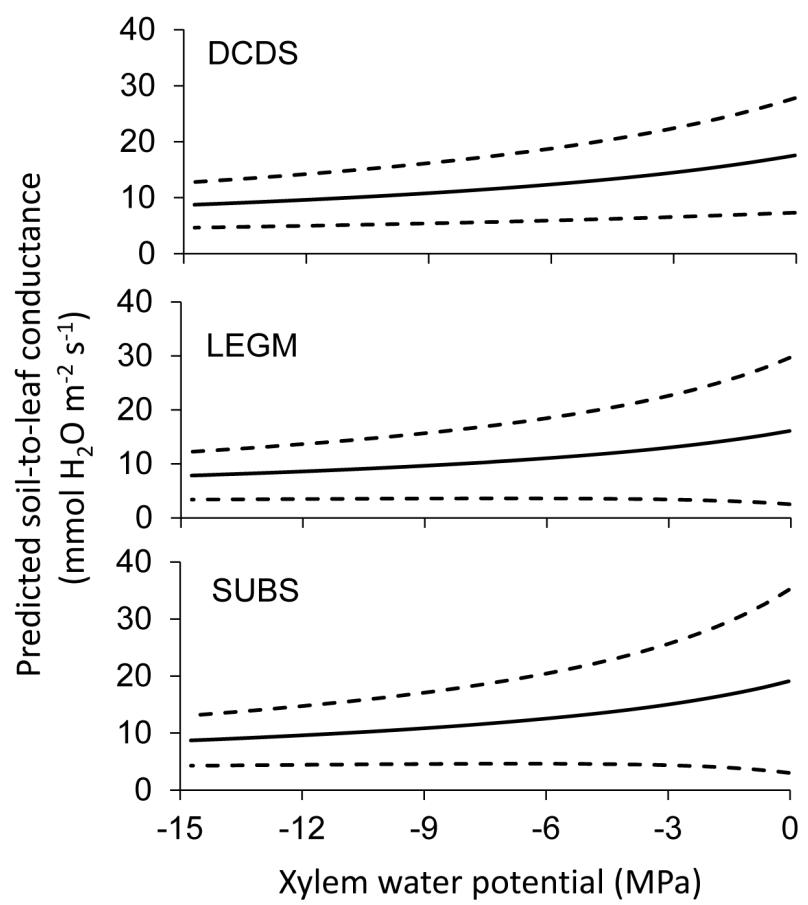

Figure 6. Predicted soil-to-leaf conductance as functions of xylem water potential based on the parameters at the observation level. The solid line stands for the mean, and the broken lines indicate one standard deviation below and above the mean.

doi:10.1371/journal.pone.0084200.g006

-14.0, and - 16.5 MPa for SUBS, LEGM, and DCDS groups, respectively, indicating that the xylem vessels of the two deciduous shrubs (DCDS and LEGM), on average, are slightly stronger than those of the SUBS.

\section{Discussion}

\section{Experimental Evidences Connected to the Results}

The behavior of stomatal conductance, driven by soil moisture and vapor pressure deficit, depends largely on the stiffness of guard cell structure, and the hydraulic conductance of plant xylem which transports water from soil to leaves. A number of literatures reported the findings of the xylem hydraulic conductivity of various plant life forms.

Kocacinar and Sage [45] experimentally measured xylem hydraulic conductivities of 16 shrub species in west America and central Asia, and found the mean hydraulic conductivities are $3.24 \times 10^{-4}$ and $0.46 \times 10^{-4} \mathrm{~kg} \mathrm{~m}^{-1} \mathrm{~s}^{-1} \mathrm{MPa}^{-1}$ for $\mathrm{C}_{3}$ and $\mathrm{C}_{4}$ species, respectively. If flow paths are about $2 \mathrm{~m} \mathrm{long}$, then the hydraulic conductance would be 9.0 and $1.3 \mathrm{mmol} \mathrm{m}^{-2} \mathrm{~s}^{-1}$ $\mathrm{MPa}^{-1}$ for $\mathrm{C}_{3}$ and $\mathrm{C}_{4}$ species, respectively. The synthesis of measurements on leaf-specific hydraulic conductivity of various plant growth forms [46] reveals that the leaf-specific whole plant conductance is in the range between 0.2 and $20 \mathrm{mmol} \mathrm{m}^{-2} \mathrm{~s}^{-1}$ $\mathrm{MPa}^{-1}$, and that the desert subshrub tends to have higher hydraulic conductance than other growth forms. The measurement of vessel density, diameter, and leaf-specific hydraulic conductance of three Caragana species in northern China [47] showed that their soil-to-leaf hydraulic conductance varied between 0.5 to $20 \mathrm{mmol} \mathrm{m}^{-2} \mathrm{~s}^{-1} \mathrm{MPa}^{-1}$. The data of Iovi et al. [48] for the Mediterranean species showed that soil-to-leaf conductance varies within a wide range up to $40 \mathrm{mmol} \mathrm{m}^{-2} \mathrm{~s}^{-1}$
$\mathrm{MPa}^{-1}$, and the herbaceous group has much higher hydraulic conductance than other groups. They also found a negative exponential decay of the hydraulic conductance with respect to decreased xylem water potential.

Our analysis at the observation level yielded $g_{p}$ (maximum potential soil-to-leaf conductivity) in the range from 1.04 to 62.13 mmol m${ }^{-2} \mathrm{~s}^{-1} \mathrm{MPa}^{-1}$, and the parameters of the three shrub functional groups are in the range from 2.05 to $5.66 \mathrm{mmol} \mathrm{m}^{-2}$ $\mathrm{s}^{-1} \mathrm{MPa}^{-1}$, comparable to the above experimental findings. Greater $g_{p}$ is an indicator of greater vessel lumen diameter, but not an indicator of greater vessel density, as the negative correlation between the two quantities found by Poorter et al. [49]. However, the greater diameter of the vessel members in general means higher potential loss of hydraulic conductivity due to cavitation and embolism of vessel members under xylem tension. This tradeoff is reflected in our obtained $C_{\lambda}$ parameter which makes the loss of conductivity proportional to the maximum conductivity. For example, the SUBS group has much higher hydraulic conductance, so that the decrease in conductance with xylem water stress is faster than the other two groups. The result is similar to those found by Iovi et al. [48].

Using finite element analysis, Cooke et al. [50] indicated that a typical stomata aperture width increases from 7 to $15 \mu \mathrm{m}$ when turgor pressure inside guard cells increases from 0 to $700 \mathrm{kPa}$. If we assume that stomatal conductance is directly proportional to stomatal aperture and that stomatal apertures of 7 and $15 \mu \mathrm{m}$ approximately correspond to typical stomatal conductance of 0.3 and $1.0 \mathrm{~mol} \mathrm{~m}^{-2} \mathrm{~s}^{-1}$, respectively, an approximation of the compliance would be $(1.0-0.3) / 0.7=1.0 \mathrm{~mol} \mathrm{~m}^{-2} \mathrm{~s}^{-1} \mathrm{MPa}^{-1}$. The model parameter $K_{\psi}$ in our analysis is a product of this compliance and stomata density, so that the apparent compliance $K_{\psi}$ should have more variation range if the variation in stomatal density is considered. We found this parameter varies between 0.088 and 1.482 with a mean of 0.613 at the observation level, and between 0.16 to $1.42 \mathrm{~mol} \mathrm{~m}^{-2} \mathrm{~s}^{-1} \mathrm{MPa}^{-1}$ at the functional group level. The result is comparable to Cook's finding.

From the findings by Leishman et al. [51,52], we know that the non-legume deciduous shrubs have lower stomatal conductance than the other two groups. The most deciduous shrubs in this study (both legume and non-legume) were found as xerophyte growing in relatively shallow soils with high water use efficiency. Their instantaneous photosynthesis can be high when soil water is abundant. However, due to the long-term drying conditions, they have to invest large amount of the assimilated products on constructing xylem for small-diameter vessels with lower $g_{p}$, which allows them to sustain the excessive drought conditions. Most legume species are thin-leaved Caragana species, which might have something to do with their relatively greater $K_{\psi}$ than the nonlegume deciduous group.

Finally, the SUBS group (Artemisia), with their less lignified stems and leaves, is shown to have the greatest compliance, and the largest potential hydraulic conductance than the two deciduous shrub groups. Thus the subshrubs are shown here to be typical drought-avoiding in most occasions. In this sense, the subshrubs share some characteristics of herbaceous plants, with stomatal conductance more responsive to variation of moistures in soil and air $[18,48]$. In other words, the subshrubs behave as an opportunist, so that they have a large stomatal conductance to accommodate the great photosynthesis when moistures are abundant in soil, but choose to close the stomata under severe drought conditions. 


\section{Implication for Macro-scale Ecosystem Dynamics}

The dynamics of leaf stomatal conductance is coupled with plant morphological structure and other variables such as leaf nutrient status and boundary layer thickness $[28,30]$. The present model should be applied and further tested within more complex ecosystem models to improve its connection with external variables.

Our hierarchical analysis showed that the functional group model is a significant improvement over the global level model, and the model at the observation level is a significant improvement over that at the functional group level. This result suggests the parameters at three levels can be used in ecosystems modeling at large, intermediate, and small scales. At regional and global scales in which we need to place all shrubs in one group, the global level parameters can be used. For small patch-scale ecosystems, parameters at the observation level are more appropriate. Modeling at intermediate mesoscales (watershed or landscape) may necessitate distinguishing the properties among shrubs types, thus the results at the level of functional groups may be applicable.

Our findings at the functional group level offered a clue to the equivocal issue in shrub-grass interaction. The process of shrub encroachment into grasslands has been understood as involving nonlinear processes in soil and plant communities, with strong positive feedbacks that consequently lead to the domination of shrubs in the previous grasslands [53]. The current understanding is that once shrubs get established and dominated in the grasslands, it is impossible for the process to reverse to restore the grasslands because of the altered competition at the community scale. However, recent studies gave a number of exceptional contradictory cases. In a 16-year exclosure (excluding from livestock grazing) established at the Erdos Sandland Ecosystem Station in northern China, it was found that a previously dominating shrub (Artemisia ordosica Krasch) decreased by $90 \%$ [54], but grasses and forbs increased substantially inside the exclosure. Another example is the Artemisia frigida Willd., a commonly observed shrub species in northern China grasslands. The proliferation of this species in the so-called typical steppes has been considered a result of overgrazing [55]. Enclosure studies in northern China showed that this shrub can be put down with appropriate management. Several studies showed that the enclosures with managed livestock grazing kept the dominance

\section{References}

1. Cramer W, Bondeau A, Woodward FI, Prentice IC, Betts RA, et al (2001) Clobal response of terrestrial ecosystem structure and function to $\mathrm{CO} 2$ and climate change: results from six dynamic global vegetation models. Global Change Biology 7: 357-373.

2. Gao Q, Yu M, Wang J, Jia H, Wang K (2004) Relationships between regional primary production and vegetation patterns. Ecological Modelling 172: 1-12.

3. Purves D, Pacala SW (2008) Predictive models of forest dynamics. Science 320: 1452-1453.

4. Hooper DU, Chapin FSI, EwelJJ, Hector A, Inchaustl P, et al. (2005) Effects of biodiversity on ecosystem functioning: a consensus of current knowledge. Ecological Monographs 75: 3-35.

5. Yu M, Gao Q (2011) Leaf-traits and growth allometry explain competition and differences in responses to climate changes in a temperate forest landscape: a simulation study. Annuals of Botany.

6. Schulze ED, Kelliher FM, Korner C, Lloyd J, Leuning R (1994) Relationships among maximum stomatal conductance, ecosystem surface conductance, carbon assimilation rate, and plant nitrogen nutrition: A global ecology scaling exercise. Annual Review of Ecology and Systematics 25: 629-660.

7. Reich PB, Walters MB, Ellsworth DS (1997) From tropics to trundra: Global convergence in plant functioning. Proceedings of the National Academy of Sciences of the United States of America 94: 13730-13734.

8. Wright IJ, Ackerly DD, Bongers F, Harms KE, Ibarra-Manriquez G, et al. (2007) Relationships among ecologically important dimensions of plant trait variation in seven Neotropical forests. Annals of Botany 99: 1003-1015.

9. Medlyn BE, Badeck FW, De Pury DGG, Barton CVM, Broadmeadow M, et al. (1999) Effects of elevated $\mathrm{CO}_{2}$ on photosynthesis in European forest species: a of the species less than $8 \%$ in the enclosures of 5,14 , and 25 years, with comparison to the $30 \%$ dominance in the heavily grazed sites $[56,57,58]$. These results contradict the current understanding of the irreversibility of shrub invasion. However, we noticed that the species in the above case studies are Artemisia subshrubs. Our results showed that there is a significant difference in stomatal behavior between the subshrubs and the deciduous shrubs. The deciduous shrubs have great advantages in resistance and tolerance to soil water stress over the grasses, which may contribute to their irreversible encroachment into grasslands. The subshrubs are less resistant and tolerant to soil moisture stress than the shrubs, and thus are less advantageous in the competition with the grasses. Our hypothesis is that when the grazing pressure is heavy, the soil cannot hold enough water because of the decreased grass roots biomass. The subshrubs start to gain dominance. However, when grazing pressure is reduced, root biomass start to increase, allowing fast infiltration of water. Consequently the soil layers tend to hold more water to allow better grass growth, and the advantage of the subshrubs over the grasses is weakened. Therefore, with appropriate management, the invasion of the subshrubs into grasslands might be reversed and the health of the grassland ecosystems might be recovered. This hypothesis has to be tested in more strictly designed experiments.

\section{Supporting Information}

Table S1 Data measured by the authors group with Licor 6400 portable gas analyzer.

(XLSX)

\section{Acknowledgments}

We appreciate Drs. Hongmei Xu, Yinghui Liu, Zhicai Zhang, Junshan Liu, and many others for the help in the field work.

\section{Author Contributions}

Conceived and designed the experiments: QG MY. Performed the experiments: QG MY CZ. Analyzed the data: QG MY. Contributed reagents/materials/analysis tools: QG MY. Wrote the paper: QG MY.

meta-analysis of model parameters. Plant, Cell and Environment 22: 14571495.

10. Reynolds JF, Smith DMS, Lambin EF, Turner BLI, Mortimore M, et al. (2007) Global desertification: building a science for dryland development. Science 316: 847-851.

11. Tong C, Yang JR, Yong WY, Yong SP (2002) Spatial pattern of steppe degraddation in Xilin River basin of Inner Mongolia. Journal of Natural Resources 17: 571-578.

12. Wigley BJ, Bond WJ, Hoffman MT (2009) Bush encroachment under three contrasting land-use practices in a mesic South African savanna. Afr J Ecol 47: $62-70$.

13. Xiong XG, Han XG, Bai YF, Pan QM (2003) Increased distribution of Caragana microphylla in rangelands and its causes and consequences in Xilin River Basin. Acta Prataculturae Sinica 12: 57-62.

14. Archer S (1994) Woody plant encroachment into southwestern grasslands and savannas: rate, patterns and proximate causes. In: Vavra M, Laycock W, Pieper R, editors. Ecological Implications of Livestock Herbivory in the West. Denver, Colorado, USA.: Society for Range Management. 13-68.

15. Archer S, Schimel DS, Holland EA (1995) Mechanisms of Shrubland Expansion - Land-Use, Climate or Co-2. Climatic Change 29: 91-99.

16. Grover HD, Musick HB (1990) Shrubland encroachment in southern New Mexico, USA: An analysis of desertification processes in the American southwest. Climatic Change 17: 305-330.

17. Neilson RP (1986) High-resolution climatic analysis and southwest biogeography. Science 232: 27-34 
18. Kemp PR, Reynolds JF, Pachepsky Y, Chen J-L (1997) A comparative modelling study of soil water dynamics in a desert ecosystem. Water Resources Research 33: 73-90.

19. Reynolds JF, Kemp PR, Ogle K, Fernandez RJ, Gao Q et al. (2006) Modeling the unique attributes of arid ecosystems: Lessons from the Jornada Basin. In: Havstad K, Huenneke LF, Schlesinger WH, editors. Structure and Function of Chihuahuan Desert Ecosystem, The Jornada Basin Long-Term Ecological Research Site. London: Oxford University Press.

20. Sperry JS, Hacke UG (2002) Desert shrub water relations with respect to soil characteristics and plant functional types. Functional Ecology 16: 367-378.

21. Nilsen ET, Sharifi MR, Rundel PW (1983) Diurnal and seasonal water relations of the desert phreatophyte Prosopis glandulosa (honey mesquite) in the Sonoran Desert of California. Ecology 64: 1381-1393.

22. Pelaez DV, Boo RM (1987) Plant water potential for shrubs in Argentina. Journal of Range Management 40: 6-9.

23. Farquhar GD, Shark TD (1982) Stomatal conductance and photosynthesis. Annual review of Plant Physiology 33: 317-345.

24. Ball JT, Woodrow IE, Berry JA (1987) A model predicting stomatal conductance and its contribution to the control of photosynthesis under different environmental conditions. In: Biggins J, editor. Progress in Photosynthesis Research. Dordrecht: Martinus Nijhoff Publishers. 221-224.

25. Leuning R (1995) A critical appraisal of a combined stomatal-photosynthesis model for $\mathrm{C}_{3}$ plants. Plant, Cell and Environment 18: 339-355.

26. Buckley TN, Mott KA, Farquhar GD (2003) A hydromechanical and biochemical model of stomatal conductance. Plant, Cell and Environment 26: 1767-1785.

27. Buckley TN, Turnbull TL, Adams MA (2012) Simple models for stomatal conductane derived from a process model: cross-validation against sap flux data. Plant and Cell Physiology 35: 1647-1662.

28. Bohrer G, Mourad H, Laursen TA, Drewry D, Avissar R, et al. (2005) Finite element tree crown hydrodynamics model $($ FETCH) using porous media flow within branching elements: A new representation of tree hydrodynamics. Water Resources Research 41: doi:10.1029/2005WR004181.

29. Gao Q Zhao P, Zeng X, Cai X, Shen W (2002) A model of stomatal conductance to quantify the relationship between leaf transpiration, microclimate and soil water stress. Plant, Cell and Environment 25: 1373-1381.

30. Gao Q Zhang X, Xu H, Huang Y (2005) Modeling seasonal and diurnal dynamics of stomatal conductance of plants in a semiarid environment. Functional Plant Biology 32: 583-598.

31. Hoffmann WA, Marchin RM, Abit P, Lau OL (2011) Hydraulic failure and tree dieback are associated with high wood density in a temperate forest under extreme drought. Global Change Biology 17: 2731-2742.

32. Fichot R, Chamaillard S, Depardieu C, Le Thiec D, Cochard H, et al. (2011) Hydraulic efficiency and coordination with xylem resistance to cavitation, leaf function, and growth performance among eight unrelated Populus deltoidesxPopulus nigra hybrids. Journal of Experimental Botany 62: 2093-2106.

33. Damunupola JW, Ratnayake K, Joyce DC, Irving DE (2011) Characterisation of xylem conduits and their possible role in limiting the vase life of cut Acacia holosericea (Mimosaceae) foliage stems. Functional Plant Biology 38: 614-623.

34. Choat B, Medek DE, Stuart SA, Pasquet-Kok J, Egerton JJG, et al. (2011) Xylem traits mediate a trade-off between resistance to freeze-thaw-induced embolism and photosynthetic capacity in overwintering evergreens. New Phytologist 191: 996-1005.

35. Tombesi S, Johnson RS, Day KR, DeJong TM (2010) Relationships between xylem vessel characteristics, calculated axial hydraulic conductance and sizecontrolling capacity of peach rootstocks. Annals of Botany 105: 327-331.

36. Jacobsen AL, Esler KJ, Pratt RB, Ewers FW (2009) Water stress tolerance of shrubs in Mediterranean-type climate regions: Convergence of fynbos and succulent karoo communities with california shrub communities. American Journal of Botany 96: 1445-1453.

37. Reyes-Santamaria I, Terrazas T, Barrientos-Priego AF, Trejo C (2002) Xylem conductivity and vulnerability in cultivars and races of avocado. Scientia Horticulturae 92: 97-105

38. Maherali H, Delucia EH (2000) Xylem conductivity and vulnerability to cavitation of ponderosa pine growling in contrasting climates. Tree Physiology 20: $859-867$

39. Lopez OR, Kursar TA, Cochard H, Tyree MT (2005) Interspecific variation in xylem vulnerability to cavitation among tropical tree and shrub species. Tree Physiology 25: 1553-1562.

40. Jacobsen AL, Pratt RB, Ewers FW, Davis SD (2007) Cavitation resistance among 26 chaparral species of southern California. Ecological Monographs 77.

41. Emanuel RE, Epstein HE, McGlynn BL, Welsch DL, Muth DJ, et al. (2010) Spatial and temporal controls on watershed ecohydrology in the northern Rocky Mountains. Water Resources Research 46.

42. Lunn DJ, Thomas A, Best N, Spiegelhalter D (2000) WinBUGS - a Bayesian modelling framework: concepts, structure, and extensibility. Statistics and Computing 10
43. Ntzoufras I (2009) Bayesian Modeling Using WinBUGS; Giudici P, Givens GH, Mallick BK, editors. Hoboken, New Jersey: John Wiley \& Sons.

44. R-Development-Cor-Team (2008) R: A language and environment for statistical computing. Vienna, Austria: R Foundation for Statistical Computing.

45. Kocacinar F, Sage RF (2004) Photosynthetic pathway alters hydraulic structure and function in woody plants. Oecologia 139: 214-223.

46. Mencuccini M (2003) The ecological significance of long-distance water transport: short-term regulation, long-term acclimation and the hydraulic costs of stature across plant life forms. Plant Cell and Environment 26: 163-182.

47. Li J, Gao Y-B, Zheng Z-R, Gao Z-l (2008) Water relations, hydraulic conductance, and vessel features of three Caragana species of the Inner Mongolia Plateau of China. Botanical Studies 49: 127-137.

48. Iovi K, Kolovou C, Kyparissis A (2009) An ecophysiological approach of hydraulic performance for nine Mediterranean species. Tree Physiology 29: 889-900.

49. Poorter L, McDonald I, Alarcon A, Licona J-C, Pena-Claros M, et al. (2010) The imprtance of wood traits and hydraulic conductance for the performance and life history strategies of 42 rainforest tree species. New Phytologist 185: 481492.

50. Cooke JR, DeBaerdemaeker JG, Rand RH, Mang HA (1977) A finite element shell analysis of guard cell deformations. Transactions of ASAE 19: 1107-1121.

51. Leishman MR, Haslehurst T, Ares A, Baruch Z (2007) Leaf trait relationships of native and invasive plants: community- and global-scale comparisons. New Phytologist 176: 635-643.

52. Wright IJ, Reich PB, Westoby M, Ackerly DD, Baruch Z, et al. (2004) The worldwide leaf economics spectrum. Nature 428: 821-827.

53. Schlesinger WH, Reynolds JF, Gunningham GL, Hueneke LF, Jarrell WM, et al. (1990) Biological feedbacks in global desertification. Science 247: 1043-1048.

54. Xiong HQ Duan JY, Zhang XS (2011) Effects of grazing exclusion on plant community characteristics in a degraded Mu Us Sandland, Inner Mongolia, northern China. Ecology and Environmental Sciences 20: 233-240.

55. Wang S, Li Y, Wang Y, Han YH (1998) Succession of Artemisia frigida rangeland and multivariation analysis under different stocking rates in Inner Mongolia. Acta Agrestia Sinica 6: 299-305.

56. Shan G, Xu Z, Ning F, Ma Y, Li L (2008) Influence of exclosure year on community structure and species diversity on a typical steppe. Acta Prataculturae Sinica 17: 1-8.

57. Liu ZG, Li ZQ (2006) Plant biodiversity of Aretemisia frigida communities on degraded grasslands under diferent grazing intensities after thirteen-year enclosure. Acta Ecologica Sinica 26: 475-482.

58. Wang J, Yang C, Wang TJ (2006) Changes of model of Artemisia frigida populations under the disturbance of grazing. Acta Ecologica Sinica 26: 960965.

59. Li J, Liu YD, Cheng GX, Chen J, Zhu JY (2000) A preliminary study on the diurnal variation of net photosynthetic rate and transpiration rate for Chimonanthus praecox. Guihaia 20: 52-58.

60. Cui XY, Chen ZZ, Du ZC (2000) Photosynthetic characteristics of a semi-arid sandy grassland community in Inner Mongolica. Acta Phytoecologica Sinica 24: 541-546.

61. Zhang SR, Ma KP, Chen LZ (2003) Response of photosynthetic plasticity of Paeonia suffruticosa to changed light environments. Environmental and Experimental Botany 49: 121-133.

62. Zhou HY, Huang ZC (1996) Seasonal variation of diurnal leaf photosynthesis and transpiration of major plant species in Maowusu sandy region. Acta Phytoecologica Sinica 20: 120-131.

63. Leng PS, Yang XH, Hu Y, Zhu HY (2000) Characterstics of Photosynthesis and transpiration of five gardening trees. Journal of Beijing Agricultural College 15: $13-18$.

64. Zhou HY (2000) Physioecological characteristics of four dominant plant species in Kerqin sandy land. Chinese Journal of Applied Ecology 11: 587-590.

65. FengJC, Zhang CL, Huang ZC, Liang HG (1997) Plant leaf gas exchange study under different environmental conditions. Northwest Botanica Sinica (Chinese) 17: 135-141.

66. Zhang LP, Teng YW, Wang XP, Huang ZC, Liu XM (1996) Periodic oscillations in stomatal conductance of a zerophyte Hedysarum scoparium. Journal of Lanzhou University (Natural Science) 32: 128-131.

67. Zhang LP, Wang XP, Liu LC, Huang ZC, Liu XM (1998) Study on gas exchange characteristics of main constructive plants Artemisia ordosica and Caragana korshinskii in Shapotou region. Acta Ecologica Sinica 18: 133-137.

68. Zhou HY, Zhang JG, Long LQ, Zhao L (2001) Photosynthesis of several dominant shrubs of genus Caragana L. in the ecotone of northern China. Journal Of Desert Research 21: 227-231.

69. Deng X, Li XM, Zhang XM, Ye WH (2002) A study of the gas exchange characteristics of four desert plants. Acta Phytoecologica Sinica 26: 605-612. 